\title{
Biodegradation of Two Synthetic Polyesters (PCL, BTA) under Salt Stress
}

\author{
Eman Barkat $^{1 *}$, Dunja-Manal M. Abou-Zeid ${ }^{2}$, Soraya A. Sabry ${ }^{2}$ \\ ${ }^{1}$ Department of Botany, Faculty of Science, University of Al Zawiya, Al Zawiya 00218-23, Libya \\ ${ }^{2}$ Microbiology Division, Botany Department, Faculty of Science, Alexandria University, Alexandria 21527, Egypt
}

Corresponding Author Email: e_hi01@yahoo.com

https://doi.org/10.18280/eesrj.070105

Received: 23 December 2019

Accepted: 5 March 2020

\section{Keywords:}

clear zone method, fungi, synthetic polymers, scanning electron microscopy, saline environment

\begin{abstract}
The target of this study was to isolate fungal strains from saline environments able to degrade two synthetic polyesters (PCL, poly (- $\varepsilon$-caprolactone) and adipic acid (1, 4butanediol, terephthalic-adipic, BTA).The clear zone method on mineral salt yeast extract medium (MSY) containing polymers was adopted to compare the degradative efficacy of isolated fungi. Scanning electron microscope as well was used to examine polymer degradation by Aspergillus flavus. Through this study a total of 22 fungal strains were isolated and identified as members of the genera Aspergillus, Acremonium, Cladosporium and Penicillium. The results indicate that isolated fungi can be divided into several groups according to their response to additional carbon and/or nitrogen sources such as glucose, peptone, casein, and others which led to an increase in the radial growth and hence an increased clear zone diameter. Scanning Electron micrographs of Aspergillus flavus confirmed the results of weight loss and exposed the presence of fungal growth on PCLS MATER Bi ZF03U films. The film surfaces exposed to the fungal strains had a rough appearance visibly different from that of the control. The surface of the films possessed numerous pits depths of varying sizes. The fungal mycelium growing on and invading the polyester material thereby cracking the film surface was also obvious. The findings of this research may contribute to realize the role of fungi in biodegradation of nondegradable synthetic polymers.
\end{abstract}

\section{INTRODUCTION}

Synthetic polymers designated as plastics have become technologically significant since the 1940s. Since then they have become an ideal material for many applications in every aspect of life and industries such as in packaging, building materials and commodities, as well as in hygiene products [1, 2]. These widespread applications are not only due to their favorable mechanical and thermal properties but mainly due to stability and durability of plastics. Indeed, these traditional petroleum-derived plastics can lead to waste disposal problems, as these materials are not readily biodegradable and are resistant to microbial degradation [2-4]. The evaluation of plastic polymer biodegradability has to be comprehensive in order to minimize harmful effects of biodegradation on the environment [5].

Polymer degrading microorganisms exist under several environmental conditions in sea, soil and sludge. In degradation processes microbes first adhere to the surface of the plastic and then colonize it followed by its biodegradation by enzymes. Enzymatic degradation is divided into two steps. Enzymes first adhere to plastics and then subsequent hydrolysis occurs that results in cleavage [6]. Several microorganisms including bacteria, actinomycetes, and fungi have been reported to biodegrade plastics under changing biotic and abiotic factors [7].

Fungi could play a remarkable role in degradation of polymers in soil due to their high ability to produce a variety of enzymes such as glucosidase, cutinase, amylase, lipase, esterase, cellulase, pectinase and hemicellulase [3]. Not only physiological studies, such as studies of enzymatic or microbial degradation and their mechanisms, but also ecological studies, such as studies of the distribution of degrading microorganisms and their ratios in the natural environment, are necessary to gain a better understanding of plastic polymer biodegradation [8, 9]. Recently, the soil fungus Aspergillus tubingensis has been reported to break down large polymers by releasing certain enzymes [10].

Little is known about the diversity two of fungi degrading synthetic polymers under salt stress and the co substrates affecting the depolymerization process .Therefore, it was aimed in this study to investigate the fungal species in two saline environments in Egypt and assess their potentiality to break down the two polymers PCL and BTA under stress conditions. It was also aimed to determine the co-substrate requirements for efficient polyester degradation and detect the changes caused in polymers films using scanning electron microscopy.

\section{MATERIALS AND METHODS}

\subsection{Microorganisms}

The fungal strains used in the present study were isolated from Siwa Oasis (soil and water), and from a salt lakes (water and sludge), Egypt. According to Elnaggar et al. [11], the salinity of Siwa soil was $\mathrm{EC}=77 \mathrm{dS} \mathrm{m}^{-1}$ (and $\mathrm{ESP}=14.62$ in average). Samples were collected in sterile containers, transferred to the lab within $24 \mathrm{~h}$ and stored at $4^{\circ} \mathrm{C}$. They were 
identified at Assiut University Mycological Center, Accession No AUMC 3200-3221.Mineral salt yeast extract medium (MSY) [12], and Malt extract agar [13] were used for isolation and degradation experiments.

\subsection{Polymers}

Two different materials were tested throughout this work: an aliphatic polyester: PCL (melting point $\mathrm{Tm}=60^{\circ} \mathrm{C}$, weightaverage molecular masses $\mathrm{Mw}=50,000 \mathrm{~g} / \mathrm{mol}$ ) obtained from Polyscience, Inc. Warrington, USA and PCL blended with starch and assigned as MaterBi ZF03U/A (melting point $\mathrm{Tm}=63^{\circ} \mathrm{C}$, weight-average molecular masses $\mathrm{Mw}=187,000$ $\mathrm{g} / \mathrm{mol}$ ), and the aliphatic-aromatic copolyester BTA 45:55(melting point $\mathrm{Tm}=100^{\circ} \mathrm{C}$, weight-average molecular masses $\mathrm{Mw}=114,000 \mathrm{~g} / \mathrm{mol}$ ) obtained from BASF, Ludwigshafen, Germany.

\subsection{Clear zone test with PCL and BTA polyesters}

Turbid agar plates containing the synthetic polyesters were prepared by an emulsion technique developed by Abou-Zeid et al. $[14,15]$. The polyester $(0.25 \mathrm{~g})$ was dissolved in $5 \mathrm{ml}$ methylene chloride and the solution was then emulsified by sonication into $250 \mathrm{ml}$ of the MSY-medium containing $1.5 \%$ (w/v) agar-agar (Difco, Detroit, Michigan, USA). The emulsion was then stirred continuously while heating for at least $30 \mathrm{~min}$ to evaporate the solvent completely. Once no more rest solvent was detected in the medium, the $\mathrm{pH}$ was adjusted to $6 \pm 0.2$. Plates were composed of two solid layers, the lower layer $(15 \mathrm{ml})$ contained mineral salt medium, whereas the upper layer $(10 \mathrm{ml})$ contained the polymer emulsion. The polymer was the only carbon source for fungal growth [16].

\subsection{Polyester depolymerization with co substrates and/or $10 \% \mathrm{NaCl}$}

To investigate the importance of co-substrates and/or $\mathrm{NaCl}$ on polymer depolymerization, the potential organisms were inoculated parallel on MSY media and on media containing one of the following substrates as a co-metabolite such as glucose (Glu), peptone (Pep), pectin (Pec), casamino acids (CASA), casein (Casein), malt extract (Malt) and trypticase soy agar (TSA) at a final concentration of $0.1 \%(\mathrm{w} / \mathrm{v})$. Medium without any co-substrate was prepared and served as a control. The individual strains were tested for their ability to grow on and depolymerize the polyesters if the media were additionally amended with $10 \% \mathrm{NaCl}$. The selection criterion was the ability to form clear zones. MSY-agar plates containing the copolyester BTA $45: 55(0.1 \% \mathrm{w} / \mathrm{v})$ or PCL $(0.1 \% \mathrm{w} / \mathrm{v})$ were inoculated in the center of the plate with sterile tooth picks from a 7 day old culture. The plates were incubated at room temperature or at $30^{\circ} \mathrm{C}, 22^{\circ} \mathrm{C}$ or $4^{\circ} \mathrm{C}$ for 8 days, respectively. The plates were examined daily for growth of colonies and clear zone formation due to fungal growth. Both radial growth increase and clear zone size were measured daily.

\subsection{Scanning electron microscopy (SEM)}

The partial disintegrated polyester films were carefully removed from the culture plates, washed and cleaned from biofilm and media residues. The clean and dry films were immersed in $4 \%(\mathrm{v} / \mathrm{v})$ glutaraldehyde in $100 \mathrm{mM}$ sodium cacodylate buffer, $\mathrm{pH} 7.2$ for primary fixation. Following primary fixation, the material was post fixed in $20 \mathrm{gL}^{-1}$ aqueous osmium tetra oxide and dehydrated in air. The dried material was gold coated and examined using a Scanning Electron Microscope Joel ISM 5300 operating at $15 \mathrm{KV}$ at the Electron Microscope Unit, Faculty of Science, and Alexandria University.

\subsection{Statistical analysis}

Each experiment was performed in duplicate and the value is the mean of the two replicates. The radial growth was calculated with Microsoft Excel 2010.

\section{RESULTS AND DISCUSSION}

\subsection{Screening for polyester depolymerization by isolated fungi}

From enrichment cultures performed with liquid MSY medium amended with PCL or BTA, a total of 22 morphologically different BTA and PCL degrading fungal isolates were isolated from Salt Lake (77\%) and Siwa (23\%) (Figure 1). These included species of Aspergillus (77\%), Cladosporium (9\%), Penicillium (9\%) and Acremonium (5\%) (Figure 1). Aspergillus flavus was the most prevalent fungus $(63.6 \%)$ isolated from salt lake water samples. These results are in good agreement with Moubasher et al. [17] and Moubasher [18] who identified Aspergillus flavus as one of the commonest fungi in soil and other substrates in Egypt. Zohri et al. [19] also identified A. flavus as a common species isolated from soil. Moreover, A. flavus has been isolated from Egyptian desert and salt marsh soils as well as agricultural soils on media amended with $15-20 \% \mathrm{NaCl}$. Moubasher et al. [20] also found that A. flavus was rated as highly halo tolerant and Aspergillus parasiticus and Aspergillus candidus have also been isolated from local desert and salt lake soils, on media containing lower salt concentrations $(5-10 \% \mathrm{NaCl})$.

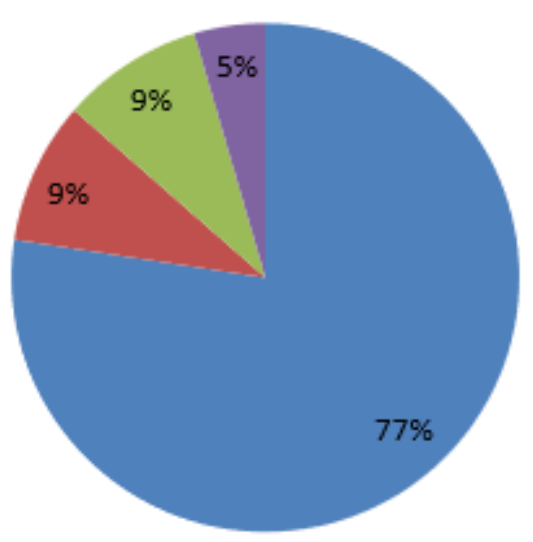

Aspergillus sp.

Cladosporium sp.

Penicillium $s p$

Acremonium sp.

Figure 1. Percentage of fungal species isolated from Siwa $(23 \%)$ and Salt Lake $(77 \%)$ degrading PCL or BTA 
Table 1. Clear zones formed $(\mathrm{cm})$ by fungal isolates on mineral salt plates containing emulsified BTA or PCL

\begin{tabular}{|ccccc|}
\hline Sub-group & Fungal species & \multicolumn{2}{c}{ Clear-zone size $[\mathrm{cm}]$} & Trend of biodegrade- \\
& & PCL & BTA & ability \\
& Aspergillus flavus & $\mathbf{7 . 5 - 1 0}$ & - & \\
& Aspergillus parasiticus & $\mathbf{9 . 6}$ & - & \\
& Aspergillus candidus & $\mathbf{2 . 5}$ & - & \\
Sub- goup 1 & Aspergillus sclerotiorum & $\mathbf{3 . 6}$ & - & PCL only \\
& Cladosporium cladosporioides & $\mathbf{2 . 6}$ & - & \\
& Penicillium brevicompactum & $\mathbf{3 . 3}$ & - & \\
& Acremonium roseolum & $\mathbf{1 . 9}$ & - & \\
\hline \multirow{2}{*}{ Sub- group 2 } & Aspergillus flavus & $\mathbf{8 . 3}$ & $\mathbf{4 . 7}$ & PCL > BTA \\
& Cladosporium cladosporioides & $\mathbf{0 . 8}$ & $\mathbf{0 . 5}$ & \\
\hline Sub- group 3 & Penicillium griseofulvum & - & $\mathbf{3 . 3}$ & BTA only \\
\hline Sub- group 4 & Aspergillus flavus & 9 & 9 & PCL= BTA \\
\hline
\end{tabular}

Acremonium roseolum strain capable of disintegrating PCL was isolated from salt lake sludge. Species of Acremonium are very common soil fungi isolated from Egyptian desert and salt marsh soils [18]. Lipases produced by Acremonium strictum [21-23] were reported to degrade the copolyester BTA 40: 60.

Cladosporium cladosporioides strains isolated from salt lake sludge successfully depolymerized PCL or BTA. Crabbe et al. [24] isolated a Cladosporium sp. based on its ability to utilize a colloidal polyester PU (Polyurethane, Impranil DLNTM) as the sole carbon and energy source and Cladosporium herbarum DSM 15967 was reported by Belal [23] to depolymerize BTA 45:55, BTA40:60, PCL and SP 4/6. The same species was effective in the biodegradation of anthracene [25].

Penicillium brevicompactum was stated as a moderately halotolerant fungus isolated from Egyptian soils with rare frequency of occurrence [20]. To our knowledge, Penicillium brevicompactum and Penicillium griseofulvum isolated in the present study have not been reported previously with respect to fungal polyester degradation (PCL and BTA). In fact the present study is the first to concentrate on fungal polyester degradation in saline environments.

\subsection{Classification of the isolates according to polyester substrate specificity}

Based on the degradation specificity/potential towards PCL and/or BTA, the fungal isolates were divided into different subgroups, while each subgroup included the strains similar in their substrate specificities towards PCL and/or BTA.

Subgroup 1 included the vast majority of the isolated fungi (18 strains) with 7 different species (Aspergillus favus, A. parasiticus, A. candidus, A. sclerotiorum, Cladosporium cladosporioides, Penicillium brevicompactum, Acremonium roseolum) all of which disintegrated only the synthetic aliphatic polyester PCL (Table 1). The clear zones formed ranged from $1.9 \mathrm{~cm}$ for Acremonium roseolum to $10 \mathrm{~cm}$ for Aspergillus flavus.

Members of subgroup 2 consisted of Aspergillus flavus and Cladosporium cladosporioides capable of disintegrating both polyesters under investigation. However, both strains formed larger clear zones within one week of incubation with PCL $(8.3$ and $0.8 \mathrm{~cm})$ than with the aliphatic aromatic copolyester BTA $(4.7$ and $0.5 \mathrm{~cm})$, respectively.

A single strain of Penicillium griseofulvum (subgroup 3) disintegrated only BTA $(3.3 \mathrm{~cm} / 8$ days). Similarly, only one Aspergillus flavus (subgroup 4) strain formed equal clear zones on PCL and BTA containing mineral salt yeast extract agar plates and exerted additionally a very high disintegration potential forming clear zones of $9 \mathrm{~cm}$ within 8 days on either PCL or BTA.

\subsection{Clear zone formation $(\mathrm{cm})$ on mineral salt agar plates containing emulsified BTA or PCL}

Preliminary studies showed that fungi grew and formed clear zones on mineral salts agar (MSY) plates containing the emulsified polymer BTA and/or PCL $(0.1 \%)$ as the sole carbon source. A. flavus successfully formed clear zones on MSY-agar plates with PCL (Figure 2.a). Cladosporium cladosporioides strain also formed clear zones on MSY-agar plates with BTA (Figure 2.b) at a temperature as low as $4^{\circ} \mathrm{C}$. The result of this study showed that polycaprolactone was preferred as a substrate compared to BTA. The capability to degrade PCL is more widely distributed in the examined environmental locations [6] than BTA. These results are in contrary with Gouda et al. [1] who reported that both PCL and BTA are readily biodegraded by the action of Fusarium solani under ambient temperature.

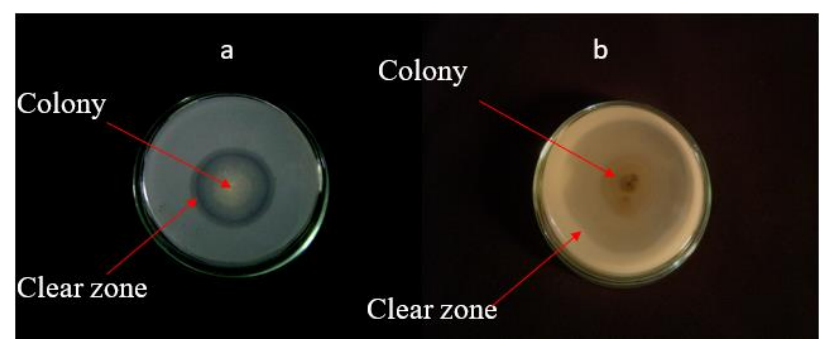

Figure 2. Clear zones on MSY-agar plates with PCL a) $A$. flavus and BTA b) Cl. cladosporioides

Clear zone formation, and thus biodegradation of polymer particles, depends on several basic requirements. The extracellular depolymerizing enzyme(s) must be excreted, followed by diffusion through the surrounding medium, and eventually an interaction between the enzyme(s) and polymer must occur. This interaction includes recognition of the surface, association of the enzyme with the polymer and chemical conversion. Eventually, depolymerization is characterized by hydrolysis of the main polyester chain $[2,26$, 27]. 

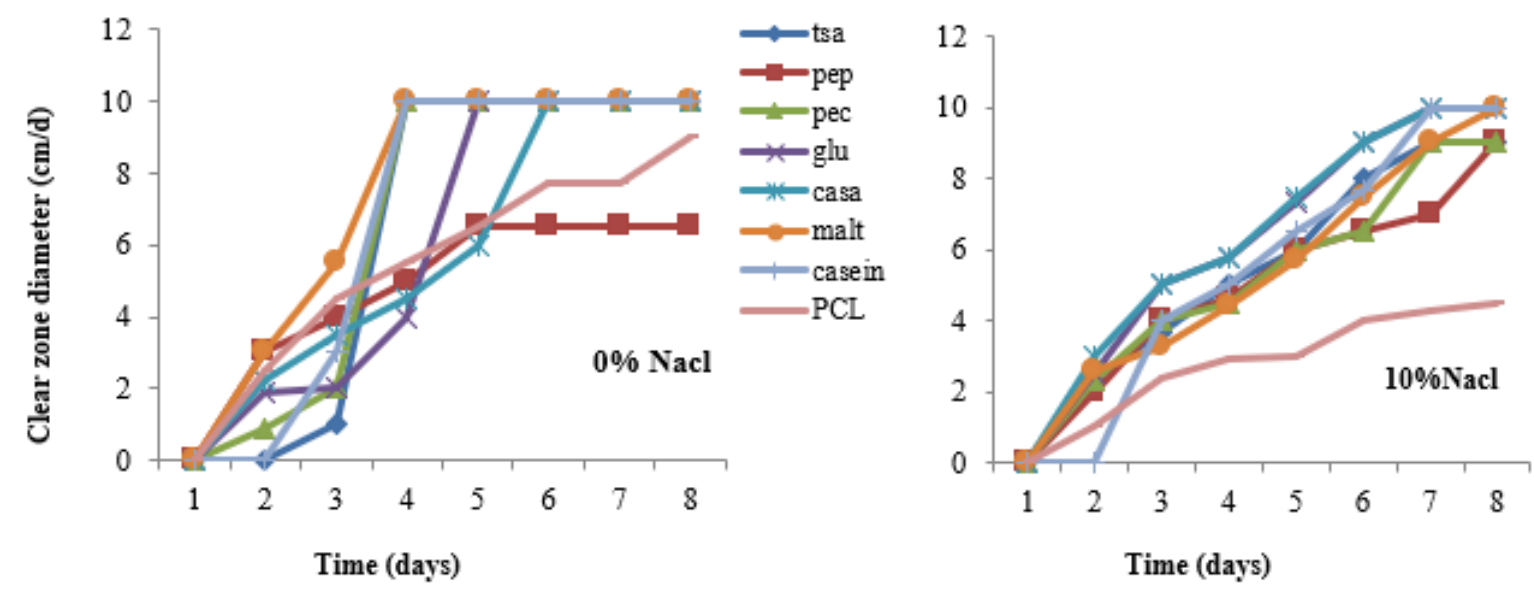

Figure 3. PCL-degrading potential of Aspergillus flavus in presence of different co-substrates $0.1 \%(\mathrm{w} / \mathrm{v})$

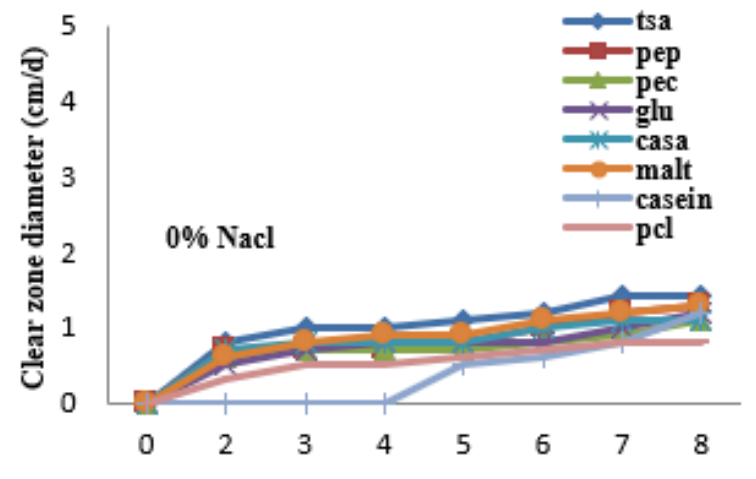

Time (days)

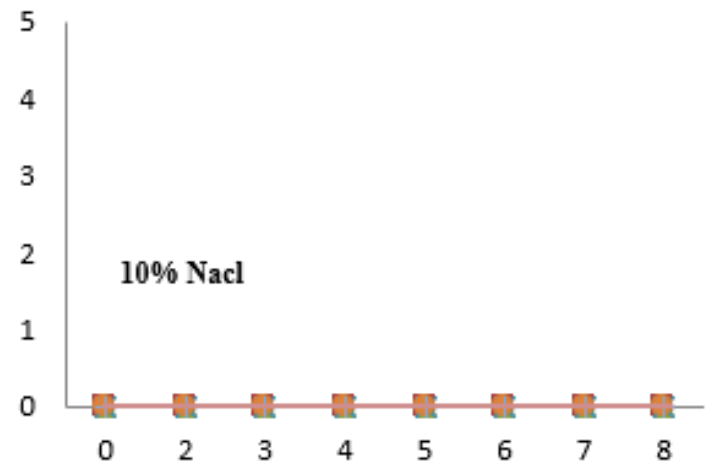

Time (days)

Figure 4. PCL-degrading potential of $C l$. cladosporioides in presence of different co-substrates $(0.1 \%$, w/v)

\subsection{Nutritional influence on enzyme induction}

No uniform pattern was observed with respect to the effect of co-substrate or $\mathrm{NaCl}$. The influence of co-substrates on growth and depolymerization activity was dependent on fungal species and type of co-substrate used. Moreover, the presence of $10 \% \mathrm{NaCl}$ affected growth and polyester degradation. The clear zone diameter for Aspergillus flavus increased in presence of co-substrates (Figure 3). Obviously, the presence of an additional carbon substrate or nitrogen source such as glucose, peptone, pectin, casamino acids, casein, malt extract and trypticase soy agar medium (TSA) enhanced depolymerization. Parallel to the increased growth, larger clear zones were observed in presence of co-substrates. It is not surprising, that more fungal growth induces larger colonies would be able to produce a higher quantity of PCL depolymerizing enzyme. Only peptone seemed to slow down the clear zone formation by Aspergillus flavus. Previous studies by Alshehrei [28] and Iram et al. [7] confirmed that different factors affecting microbial degradation of plastics such as physical and physiochemical factors, the nature of organisms and type of additives added. In addition, hydrolase enzymes proceed the hydrolytic reactions which include a large number of enzymes e.g. phosphatase, lipase, esterase, glycosidase and many others [7], that could affect the rate of degradation of plastics.

Cladosporium cladosporoides comprised the slowest growth compared to all other tested fungal strains and the different co-substrates tested did not markedly affect the clear zone formation (Figure 4). The effect of salt stress (10\% $\mathrm{NaCl}$ ), however, was very pronounced since it inhibited growth on PCL in absence of co substrates. The presence of $10 \% \mathrm{NaCl}$, did not markedly affect clear zone diameter except when PCL was the only carbon source. The addition of $10 \%$ $\mathrm{NaCl}$ represented a stress factor if additional co substrates were lacking from the growth medium. For example, the potential of PCL depolymerization by Aspergillus flavus decreased to about $50 \%$ in absence of co-substrates. This clearly indicates that the presence of co-substrates obviously successfully compensated the negative effect of $\mathrm{NaCl}(10 \%)$. Despite the rapid depolymerization of the PCL homopolyester and the synthetic aliphatic-aromatic copolyester BTA, only poor growth of the fungus could be observed on mineral salt agar with a polymer as the sole carbon source as indicated by the radial growth increase. This suggests that the fungi generally are not able to completely metabolize the oligomers and monomers derived from the depolymerization of the aliphatic-aromatic copolyester. As PCL and BTA polyesters are abiotic synthetic materials, it is not likely that microorganisms have been specialized to this kind of carbon source. However, they are adapted to the use of other, similar polyester structures containing aromatic components like those in cutin or lignocelluloses.

\subsection{Nutritional effects on BTA depolymerization}

Two strains of Cladosporium cladosporoides and Aspergillus flavus were not able to degrade synthetic polyester 
such as BTA under salt stress even in the presence of cosubstrates. Although PCL and BTA have been shown to be depolymerized by a number of fungi through their extracellular enzymes, PCL is certainly much more susceptible to fungal attack which was expected from earlier investigations [14, 15, 23].These results agree with Vroman and Tighzert [8] and Pathak [29] who indicated that enzymes and fungi easily biodegrade PCL. Polyesters with such a large aromatic compound fraction have also been shown to degrade slowly in composting tests [30]. This does not have to be a consequence of chemical composition alone, but maybe caused by its increased crystallinity or structural properties as well [31]. The lower or slower biodegradability of BTA can be explained on a biochemical level. The depolymerization products of both aliphatic and aliphatic-aromatic polyesters are monomers and oligomers. While the monomers and oligomers of aliphatic polyesters are readily water soluble, the aromatic oligomers (oligo esters with one and two terephthalate units), are slightly water soluble [7]. Yet, metabolization of the polyester degradation products by microorganisms depends on their solubility and its corresponding diffusability. Therefore, all monomers are rapidly metabolized by microorganisms. The final degradation of longer aromatic oligomers, with a significantly slower degradability, comprises a slower/minor solubility, and hence is metabolized at a much slower rate [32-34]. This result is similar to Leja and Lewandowicz [35] who found that the existence of microbial communities able of degrading aromatic materials with sulfate as the electron acceptor has not yet been confirmed. During the depolymerization of BTA, purely aromatic dimers, trimers or oligomers are formed which contain ester bonds between two terephthalic acid units [15, 29, 33]. However, up to now it is not clear if any enzymes exist, which are principally able to cleave ester bonds between two terephthalic acids (aromatic dimers, trimers or oligomers). Probably chemical hydrolysis plays role in the breakdown of such aromatic oligomeric intermediates [34, 36].

\subsection{Depolymerization of PCL and scanning electron microscopy of polyester films}

The examination of the surface microstructure of the plastic films and the consequences of degradation was investigated.
When the fungal inoculum was placed below the polyester films at $30^{\circ} \mathrm{C}$, the maximum weight loss for Aspergillus flavus $(57.1 \%)$ and Cladosporium cladosporoides at $22^{\circ} \mathrm{C}(56.4 \%)$ was obtained (data not shown). The residual polyester film material exposed to A.flavus or Cl. Cladosporoides were taken as examples and examined by scanning electron microscopy. Morphological alterations of the polymer surface prove fungal hydrolysis via surface active polyester depolymerases. This is due to the fact that the ability of a fungal strain to degrade PCL-S MATER Bi ZF03U/A films depends on the secretion of specific depolymerizing enzymes that hydrolyze the polymer chains on the surface to water soluble products $[3,37$, 38]. In addition, it was attempted to explain the cessation of degradation by surface properties or alteration. PCL-S MATER Bi ZF03U/A polyester films which had been partially degraded in the experiment described above were processed for scanning electron microscopy. The surface of the uninoculated control film incubated on sterile plates was smooth (Figures 5a, 6.a). This indicates that incubation of the PCL-S MATER Bi ZF03U/A films on sterile media had no effect on the surface of the polymer. On the other hand, the film surfaces exposed to A. flavus or Cl. cladosporoides for 10 to 16 days had a rough appearance clearly different from that of the control. The surface of the films possessed numerous pits of varying sizes. However, zones of native film surfaces also appeared spread over the film (Figures 5 and 6). Moreover, the SEM micrographs of the surface showed evidence of filamentous fungal strain whose hyphae adhered to the polymer surface even after cleaning treatment. Even spores appeared scattered over the polyester film surface. The ability of the fungus to degrade PCL-S MATER Bi ZF03U/A depends on the enzymatic hydrolysis of the polymer to water soluble products and polymer erosion proceeds via surface dissolution. It is obvious that amorphous regions of the polymer are more rapidly degraded than the crystalline ones. Similar results were found by Kumagai et al. [39]; Ghavimi et al. [40]; Nishida and Tokiwa [37] as well as Molitoris et al. [22]. However, no logic explanation for the cessation of degradation of the polyester films was deducible from the SEM micrographic examinations. Especially, since enough native and amorphous material remained on the polyester surfaces which could be further degraded.

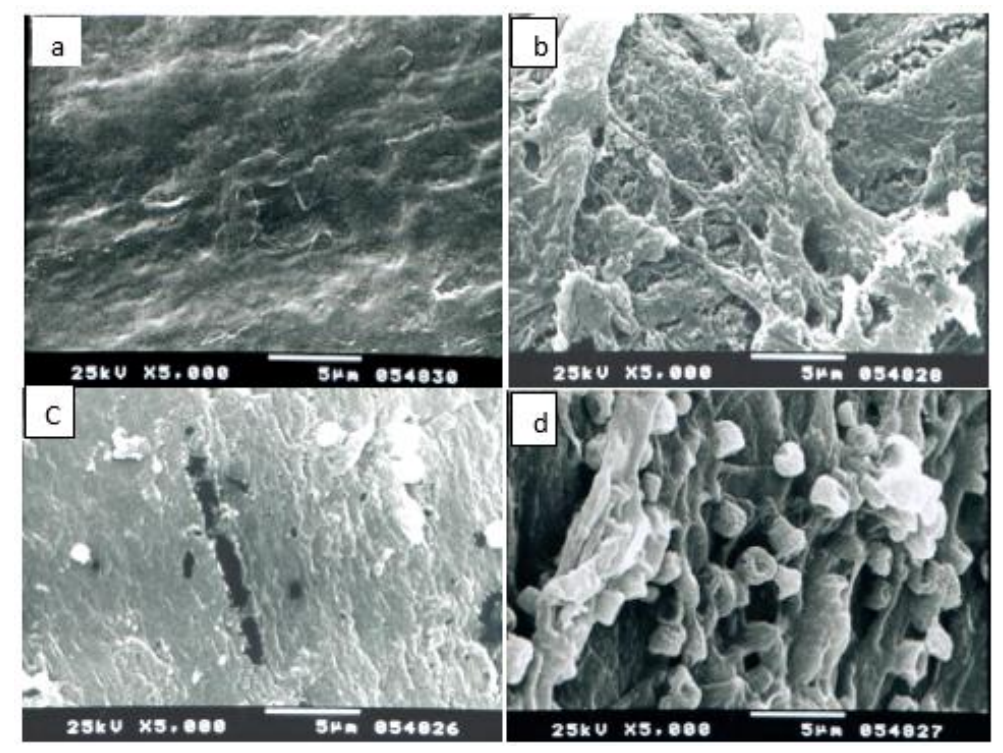

Figure 5. SEM micrograph of PCL-S MATER Bi ZF03U/A films exposed to Aspergillus flavus 


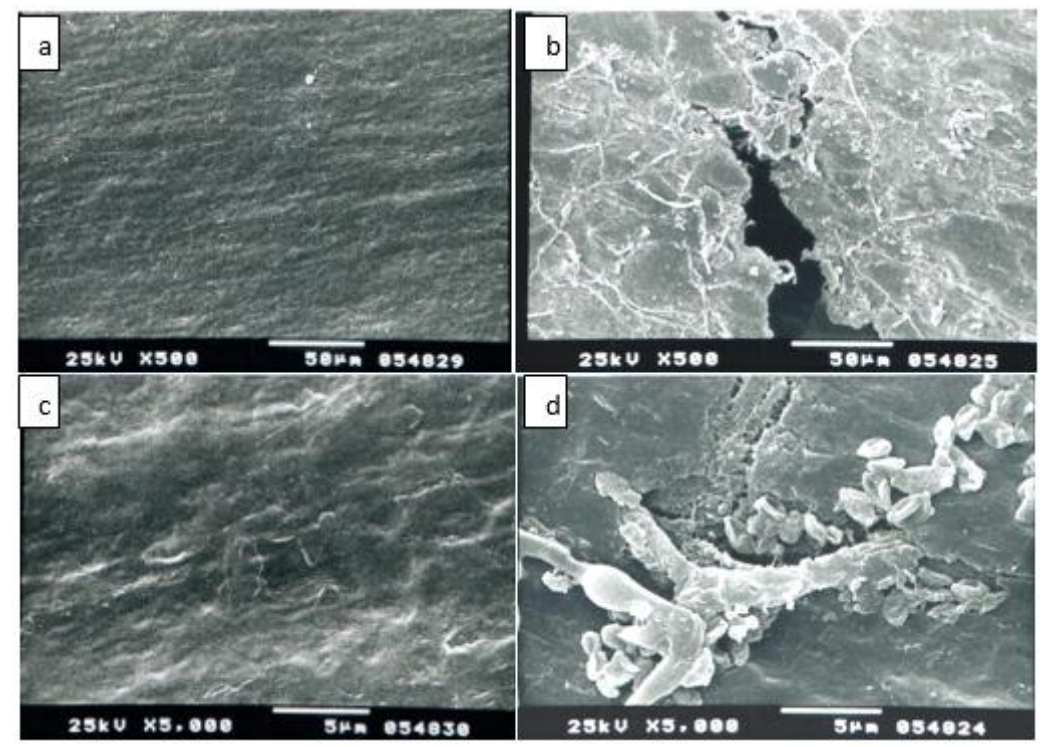

Figure 6. SEM micrograph of PCL-S MATER Bi ZF03U/A films exposed to Cladosporium cladosporoides

\section{CONCLUSION}

The results obtained in this study provide helpful information about the degradation behavior of polyester materials under harsh conditions, which is important for recycling of biodegradable plastics in the environment. To test the biodegradability of polymers, a lot of methods have been used, such as clear zone formation on mineral salt agar plates containing emulsified BTA or PCL and a study on nutritional influence on enzyme induction was performed. These methods improve both the biodegradation rate and the mechanical properties of the final products. In addition, this study demonstrated the use of fungal species as an alternative expression system for production of the multi-polyesterdegrading enzyme of PCL and BTA, and provided insights on its catalytic properties on surface degradation contributing to further biotechnological application of this enzyme. The result of microscopic observation using SEM and all the results prove the degradability of the polyesters under test. The data obtained in this study lead to the suggestion that enzymes secreted by fungi attack preferentially the amorphous or less ordered region rather than the crystalline or more ordered region, because the enzymes are able to migrate more readily into the less ordered region than the more ordered region. This is probably attributed to the preferential degradation and removal of amorphous regions. Additional studies with obtained strains should provide interesting insights into the mechanisms for aerobic polyester degradation under environmental stresses. Further studies involving optimization of factors affecting depolymerization processes is recommended which will be considered in the future.

\section{ACKNOWLEDGEMENT}

The work described in this paper was undertaken while I was enrolled as a student for the degree of Master at Microbiology and Botany Department, Faculty of Science, Alexandria University, Egypt under the supervision of Dr. Dunja-Manal M. Abou-Zeid and Professor Soraya A. Sabry. The authors are also grateful to Alexandria University and the Libyan Government for the financial support of the first author.

\section{REFERENCES}

[1] Gouda, M.K., Swellam, A.E., Omar, S.H. (2012). Biodegradation of synthetic polyesters (BTA and PCL) with natural flora in soil burial and pure cultures under ambient temperature. Research Journal of Environmental and Earth Sciences, 4(3): 325-333.

[2] Siracusa, V. (2019). Microbial degradation of synthetic biopolymers waste. Polymers, 11(6): 1066. http://dx.doi.org/10.3390/polym11061066

[3] Belal, E.B. (2013). Biodegradation of aliphatic-aromatic coplyester under thermophilic conditions. Research Journal of Environmental and Earth Sciences, 5(11): 677-690. http://dx.doi.org/10.19026/rjees.5.5723

[4] Padinjakkara, A., Thankappan, A., Souza Jr, F. G., Thomas, S. (Eds.). (2018). Biopolymers and Biomaterials. CRC Press. https://doi.org/10.1201/9781315161983

[5] Ahmed, T., Shahid, M., Azeem, F., Rasul, I., Shah, A.A., Noman, M., Muhammad, S. (2018). Biodegradation of plastics: current scenario and future prospects for environmental safety. Environmental Science and Pollution Research, 25(8): 7287-7298. https://doi.org/10.1007/s11356-018-1234-9

[6] Tokiwa, Y., Calabia, B.P., Ugwu, C.U., Aiba, S. (2009). Biodegradability of plastics. International journal of molecular sciences, $10(9)$ : $3722-3742$. https://doi.org/10.3390/ijms10093722

[7] Iram, D., Riaz, R.A., Iqbal, R.K. (2019). Usage of potential micro-organisms for degradation of plastics. Open J Environ Biol, 4(1): 007-0015. https://doi.org/10.17352/ojeb.000010

[8] Vroman, I., Tighzert, L. (2009). Biodegradable polymers. Materials, $2(2)$ : https://doi.org/10.3390/ma2020307

[9] Liu, Y., Zhan, Z., Ye, H., Lin, X., Yan, Y., Zhang, Y. (2019). Accelerated biodegradation of PLA /PHB blended nonwovens by a microbial community. RSC Advances, $\quad 9(18)$ : 10386-10394. https://doi.org/10.1039/C8RA10591J

[10] Baker, M. (2018). How to eliminate plastic waste and plastic pollution with science and engineering. Science. 
https://interestingengineering.com/how-to-eliminateplastic-waste-and-plastic-pollution-with-science-andengineering.

[11] Elnaggar, A., El-Hamidi, K., Mousa, M., Albakry, M. (2017). Mapping soil salinity and evaluation of water quality in Siwa Oasis using GIS. Journal of Soil Sciences and Agricultural Engineering, 8(1): 9-19. https://doi.org/10.21608/JSSAE.2017.37078

[12] Oda, Y., Asari, H., Urakami, T., Tonomura, K. (1995). Microbial degradation of poly(3-Hydroxybutyrate) and polycaprolactone by filamentous fungi. Journal of Fermentation Bioengineering, 80(3): 265-269. https://doi.org/10.1016/0922-338X(95)90827-M

[13] Domsch, K.H., Gams, W., Anderson, T.H. (1980). Compendium of Soil Fungi. Volume 1. Academic Press (London) Ltd, London, UK.

[14] Abou-Zeid, D.M., Müller, R.J., Deckwer, W.D. (2001). Degradation of natural and synthetic polyesters under anaerobic conditions. J. Biotechnol, 86 (2): 113-126. https://doi.org/10.1016/S0168-1656(00)00406-5

[15] Abou-Zeid, D.M., Müller, R.J., Deckwer, W.D. (2004). Biodegradation of aliphatic homopolyesters and aliphatic-aromatic copolyesters by anaerobic microorganisms. Biomacromolecules, 5(5): 1687-1697. https://doi.org/10.1021/bm0499334

[16] Augusta, J., Müller, R.J., Widdecke, H. (1993). A rapid evaluation plate-test for the biodegradability of plastics. Appl. Microbiol. Biotechnol, 39: 673-678. https://doi.org/10.1007/BF00205073

[17] Moubasher, A.H., Abdel-Hafez, S.I.I., Maghraby, O.M.O. (1985). Studies on soil mycoflora of WadiBirEl-Ain, Eastern Desert, Egypt. Gryptogamie Mycol, 6: 129-143.

[18] Moubasher, A.H. (1993). Soil fungi in Qatar and other Arab countries. Center for Scientific and Applied Research, DohaUniversity, Doha, Qatar.

[19] Zohri, A.N.A., Elkhateeb, W.A., Mazen, M.B., Hashem, M., Daba, G.M. (2014). Study of soil mycobiota diversity in some new reclaimed areas, Egypt. Egyptian $\begin{array}{lll}\text { Pharmaceutical Journal, } & \text { 13(1): } 58 .\end{array}$ https://doi.org/10.4103/1687-4315.135598

[20] Moubasher, A.H., Abdel-Hafez, S.I.I., Bagy, M.M.K., Abdel-Sater, M.A. (1990). Halophilic and halotolerant fungi in cultivated, desert and salt marsh soils from Egypt. Acta Mycologica, 27: 65-81. https://doi.org/10.5586/am.1990.013

[21] Okeke, C.N., Okolo, B.N. (1990). The effect of cultural conditions on the production of lipase by Acremonium strictum. Biotechnology Letters, 12(10): 747-750. https://doi.org/10.1007/BF01024733

[22] Molitoris, H.P., Moss, S.T., De Koning, G.J.M., Jendrossek, D. (1996). Scanning electron microscopy of polyhydroxyalkanoate degradation by bacteria. Applied microbiology and biotechnology, 46(5-6): 570-579. https://doi.org/10.1007/s002530050863

[23] Belal, E.S.B.A.E. (2003). Investigations on the biodegradation of polyesters by isolated mesophilic microbes (Doctoral dissertation). https://publikationsserver.tubraunschweig.de/receive/dbbs_mods_00001501

[24] Crabbe, J.R., Campbell, J.R., Thompson, L., Walz, S.L., Schultz, W.W. (1994). Biodegradation of a colloidal ester-based polyurethane by soil fungi. Inter. Biodet. Biodeg, 33(2): 103-113. https://doi.org/10.1016/0964-
8305(94)90030-2

[25] Krivobok, S., Miriouckine, E., Seigle-Murandi, F., Benott-Guyod, J.L. (1998). Biodegradation of anthracene by soil fungi. Chemosphere, 37(3): 523-530. https://doi.org/10.1016/S0045-6535(98)00067-8

[26] Tokiwa, Y., Suzuki, T. (1981). Hydrolysis of copolyesters containing aromatic and aliphatic ester blocks by lipase. Journal of Applied Polymer Science, 26(2): 441-448. https://doi.org/10.1002/app.1981.070260206

[27] Mochizuki, M., Mukai, K., Yamada, K., Ichise, N., Murase, S., Iwaya, Y. (1997). Structural Effects upon Enzymatic Hydrolysis of Poly (butylene succinate-coethylene succinate)s. Macromol, 30(24): 7403-7407. https://doi.org/10.1021/ma970036k

[28] Alshehrei, F. (2017). Biodegradation of synthetic and natural plastic by microorganisms. Journal of Applied \& Environmental Microbiology, 5(1): 8-19. https://doi.org/10.12691/jaem-5-1-2

[29] Pathak, V.M. (2017). Review on the current status of polymer degradation: A microbial approach. Bioresources and Bioprocessing, 4(1): 15. https://doi.org/10.1186/s40643-017-0145-9

[30] Witt, U., Müller, R.J., Deckwer, W.D. (1995). Biodegradation of polyester copolymers containing aromatic compounds. Journal of Macromolecular Science, Part A: Pure and Applied Chemistry, 32(4): 851-856. https://doi.org/10.1080/10601329508010296

[31] Kuwabara, K., Gan, Z., Nakamura, T., Abe, H., Doi, Y. (2002). Crystalline/Amorphous Phase Structure and Molecular Mobility of Biodegradable Poly(butylene adipate-co-butylene terephthalate) and Related Polyesters. Biomacromolecules, 3(2): 390-396. https://doi.org/10.1021/bm0156476

[32] Marten, E., Müller, R.J., Deckwer, W.D. (2003). Studies on the enzymatic hydrolysis of polyesters I. Low molecular mass model esters and aliphatic polyesters. Polymer Degradation and Stability, 80(3): 485-501. https://doi.org/10.1016/S0141-3910(03)00032-6

[33] Bastioli, C. (Ed.). (2005). Handbook of Biodegradable Polymers. iSmithers Rapra Publishing. http://dx.doi.org/10.1515/9781501511967

[34] Almeida, B.C., Figueiredo, P., Carvalho, A.T. (2019). PCL enzymatic hydrolysis: A mechanistic study. ACS Omega, 4(4): https://doi.org/10.1021/acsomega.9b00345

[35] Leja, K., Lewandowicz, G. (2010). Polymer biodegradation and biodegradable polymers - a review. Polish Journal of Environmental Studies, 19(2): 255-266.

[36] Gross, R.A.,Kalra, B. (2002). Biodegradable polymers for the environment. Science, 297(5582): 803-807. https://doi.org/10.1126/science.297.5582.803

[37] Nishida, H., Tokiwa, Y. (1993). Distribution of poly ( $\beta$ hydroxybutyrate) and poly ( $\varepsilon$-caprolactone) aerobic degrading microorganisms in different environments. Journal of Environmental Polymer Degradation, 1(3): 227-233. https://doi.org/10.1007/BF01458031

[38] Müller, R.J. (2005). Biodegradability of polymers: Regulations and methods for testing. Biopolymers Online: Biology ${ }^{\bullet}$ Chemistry ${ }^{\circ}$ Biotechnology• Applications. https://doi.org/10.1002/3527600035.bpola012

[39] Kumagai, Y., Kanesawa, Y., Doi, Y. (1992). Enzymatic degradation of microbial poly (3-hydroxybutyrate) films. 
Die Makromolekulare Chemie, 193(1): 53-57. https://doi.org/10.1002/macp.1992.021930105

[40] Ghavimi, S.A.A., Ebrahimzadeh, M.H., Solati-Hashjin, M., Abu Osman, N.A. (2015). Polycaprolactone/starch composite: Fabrication, structure, properties, and applications. Journal of biomedical materials research Part A, 103(7):

https://doi.org/10.1002/jbm.a.35371 2482-2498. 